\title{
MINERVA: Model drIveN and sErvice oRiented Framework for the Continuous Business Process improVement and relAted Tools
}

\author{
Andrea Delgado ${ }^{1}$, Francisco Ruiz ${ }^{2}$, Ignacio García-Rodríguez de Guzmán ${ }^{2}$, \\ and Mario Piattini ${ }^{2}$ \\ ${ }^{1}$ Computer Science Institute, Faculty of Engineering, \\ University of the Republica Julio Herrera y Reissig 565, \\ CP 11300, Montevideo,Uruguay \\ ${ }^{2}$ Technologies and IS Depto., Faculty of Computer Science, \\ University of Castilla-La Mancha, Paseo de la Universidad No.4, \\ CP 13071, Ciudad Real, España \\ adelgado@fing.edu.uy, \\ \{francisco.ruizg, ignacio.grodriguez, mario.piattini\}@uclm.es
}

\begin{abstract}
The importance and benefits of Business Process Management (BPM) for organizations are nowadays broadly recognized, as not only the business area but also the information technology one are embracing and adopting the paradigm. The implementation of business processes as services helps in reducing the gap between these two areas, easing the communication and understanding of business needs. Although there is a general agreement on the benefits of the joint application of these two paradigms, some issues still need to be addressed; being a key one the automatic generation of services from business process models. In this article, we present MINERVA framework which applies Model Driven Development (MDD) and Service Oriented Computing (SOC) paradigms to business processes for the continuous business process improvement in organizations, supporting the different stages defined in the business process life cycle from modeling to evaluation of its execution.
\end{abstract}

Keywords: business process, Business Process Management (BPM), Service Oriented Computing (SOC), Model Driven Development (MDD), improvement.

\section{Introduction}

The progressive adoption of the Business Process Management (BPM) [1][2] paradigm by organizations, defined as the activities that organizations do to optimize or adapt their business processes to the new organizational needs, puts the spotlight on the business process lifecycle as defined in [3][4][5], and on tools and technologies to support each stage. A business process is defined as a set of activities performed in coordination in an organizational environment to reach a business objective [3]. BPM Systems (BPMS) are generic software systems driven by explicit representations of business processes to coordinate their execution [3]. The implementation of business processes as services helps in reducing the gap between business and Information 
Technology (IT) areas, easing the communication and understanding of business needs. It also promotes the independence between the definition and modeling of business processes, and their implementation into a specific technology, allowing changes in each one with minimal impact on the other.

Service Oriented Computing (SOC) refers to software development based on services to support distribute low cost interoperable evolving and massive applications [6]. A service provides an implementation which provides business logic and data, a service contract which specifies the operations and pre and post conditions, and an interface to expose the functionality [7]. Service Oriented Architecture (SOA) [7][8] is a software architecture style which constitutes an specific realization of SOC, implemented in general by Web Services (WS) [9]. Model Driven Development (MDD) bases the software development on models, using as first order artifacts metamodels, models and languages which allow transformations between them [10][11]. Model Driven Architecture (MDA) [12] is a standard realization of MDD by the Object Management Group (OMG) [13], where the main characteristic is model transformation defined as the process of converting one model into another model of the same system.

MINERVA stands for "Model drIveN \& sErvice oRiented framework for the continuous business process improVement \& relAted tools", and aims to provide a framework comprising methodologies, concepts and tools for the automated development of service oriented solutions from business processes in organizations, combining the application of SOC and MDD paradigms to business process. It is defined to support the business process lifecycle as defined in [3], covering the four phases of: Design and Analysis, Configuration, Enactment and Evaluation. The rest of the document is organized as follows: section 1 presents the MINERVA proposal describing its general elements, in section 2 the dimensions of MINERVA are detailed showing its main elements; in section 3 the related work is mentioned and finally in section 4 the conclusions and future work are discussed.

\section{MINERVA Proposal}

MINERVA (Model drIveN \& sErvice oRiented framework for the continuous business process improVement \& relAted tools) constitutes a framework for the business process improvement based on the business process lifecycle [3] that is defined in three dimensions: conceptual, methodological [14] and tool support. It also takes into account the Business Process Maturity Model (BPMM) [15] OMG standard, and measures for the design [4] and execution of business processes [16], which will drive the improvement effort in the business process lifecycle. Starting from the modeling of business processes in the Business Process Modeling Notation (BPMN) [17], MINERVA automatically obtains from this model a services model expressed in Service Oriented Architecture Modeling Language (SoaML) [18] by means of Query/Views/ Transformations (QVT) [19] transformations, to the execution of processes expressed in BPEL [20] or XPDL [21] in a suitable process engine. Fig.1 shows the general framework for the derivation of services from business process. 


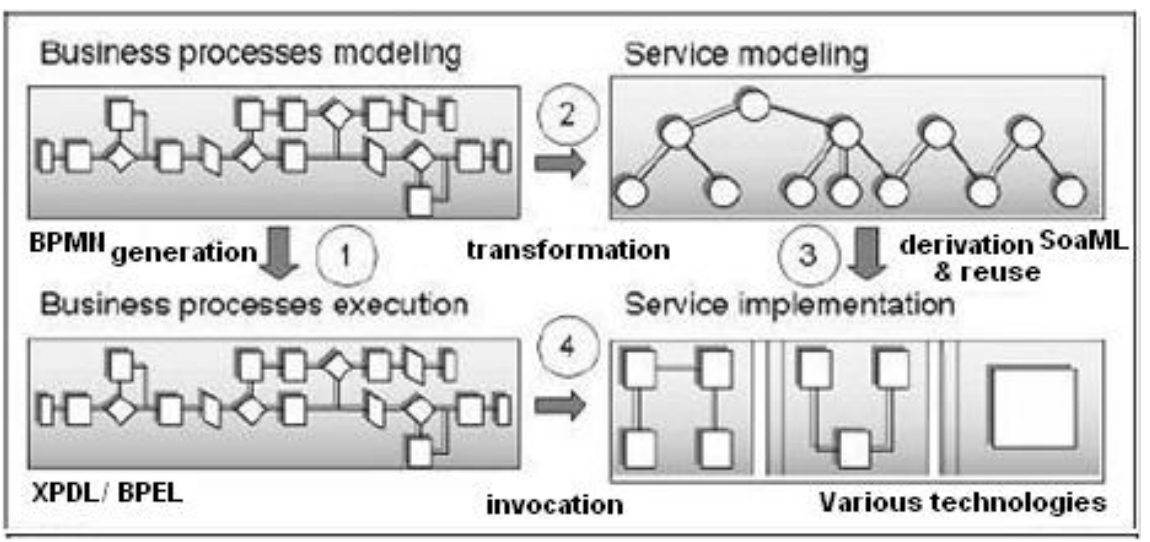

Fig. 1. Business processes and services relationships in MINERVA

Fig. 1 illustrates the steps for the automatic derivation of services from business processes, which is integrated in a service oriented methodology to guide the development of services from business processes. The proposal begins with the modeling of business processes in BPMN, shown on the top left corner in figure 1, which constitutes the input to the defined development process. From this model two complementary models are obtained: (1) automatic generation of the process specification in some executable/interpretable language like BPEL/XPDL, and (2) (almost) automatic generation of the services design model to realize the process in SoaML profile. From the services design model the implementation model is automatically obtained in step (3) for the selected technological platforms. Finally, both implementations are related to connect the business process execution: from business processes in BPEL/XPDL running in a process engine, components implementing the obtained services are invoked. To support the business process continuous improvement, it is necessary to add elements to the framework, as we need to collect data in the form of measures about relevant aspects, which can come from two sources: business process models and execution. We will integrate both types of measures: to verify models from which to obtain the services prior to the generation, and to analyze execution applying techniques such as Process Mining[22]. A continuous improvement process is being defined to support the improvement cycle to be followed to obtain the defined business goals of the organization.

\section{Dimensions of MINERVA}

The framework integrates elements into three dimensions: conceptual, methodological and tool support, comprising different elements that constitute the basis for the proposal, which are described in the following. 


\subsection{Conceptual Dimension}

The conceptual dimension aims to define concepts, terminology and relations between them to be used all over the framework. An ontology defines the relevant elements (concepts, relationships) for the domain under study, providing meaning to the vocabulary and formalizing restrictions on its use [23]. The main objectives for the inclusion of an ontology in the MINERVA proposal are: to define, organize and reuse knowledge about concepts involved in the management of business processes and their life cycle, as well as their design and implementation based on services and the relationship between them. It also establishes the basis for defining transformations from business process to service metamodels as in Business Process Metamodel Definition (BPMD) [24] and SoaML.

Based on the business processes lifecycle [3], we have identified five groups for the main conceptual elements required in BPM. Therefore, sub-ontologies are defined for: modeling, simulation, execution, measurement and evaluation of business processes. To support service orientation, there are two main conceptual groups which define the sub-ontologies for service-oriented modeling and execution. The Service Oriented Modeling sub-ontology ( $\mathrm{SOMsO}$ ) corresponds to the Business Process Modeling sub-ontology (BPMsO) meaning that the elements from the first one trace to elements from the second one. On the other hand, the Business Process Execution (BPEsO) sub-ontology "use" the Service Oriented Execution sub-ontology (SOEsO), where an execution of a business process in a business process engine will invoke the execution of corresponding services. The Business Process Measuring sub-ontology (BPMEsO) integrates measures for business process models and execution [16] adding elements adapted from the Software Measurement Ontology (SMO) [25]. The Business Process Evaluation sub-ontology (BPEVsO) uses measuring and execution sub-ontologies, defining other elements like Process Mining for execution logs analysis. The Business Process Simulation sub-ontology (BPSsO) defines elements to simulate and understand various characteristics of models prior to their execution.

So far, we have an initial definition of the BPMsO and the SOMsO which we briefly describe in the following, the complete definition can be seen in [26]. For business process modeling, the main references are the BPMN and BPDM OMG standards from which their defined concepts were taken. In service orientation there are many sources, from which were evaluated: SoaML [18] from OMG, Web Services Architecture (WSA) [9] from W3C, Service Oriented Architecture Reference Model (SOA RM) [27] from OASIS, Service Oriented Architecture Ontology (SOA O) [28] from Open Group. As shown in Fig. 2, the BPMN known grouping for BP elements is used: flow objects, connector objects, swimlanes (pool/lanes) and artifacts. As a key element of the service model the Service concept is identified, which is composed of an Implementation providing the required functionalities, a Contract that specifies the Operations provided and an Interface that offers the functionality. Provider and Consumer Agents exchange the defined Messages. The main relations between the BPMsO and the SOMsO refer to the correspondence between its key elements, for example activities (simple, sub-process) correspond to services, and pools correspond to participants, among others. 


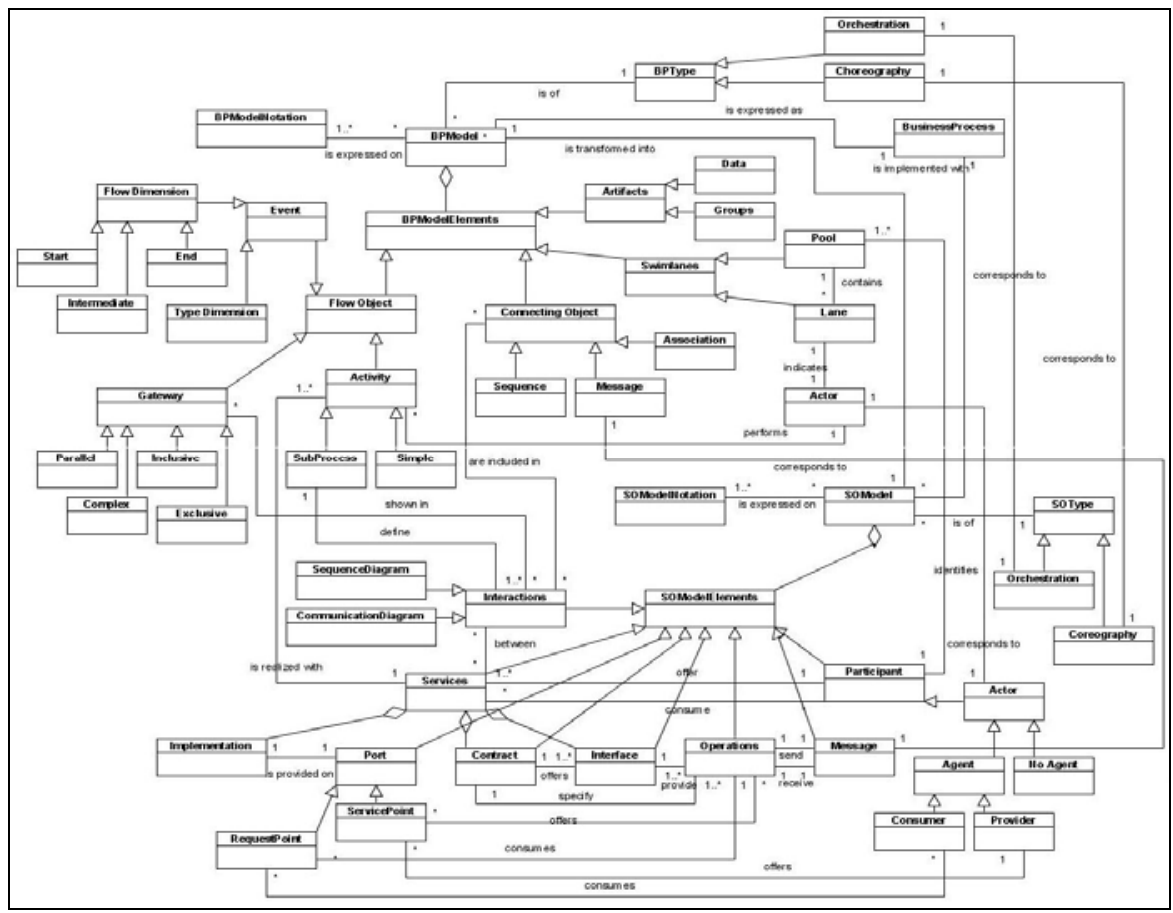

Fig. 2. Business Processes and Service Oriented Modeling sub-ontologies

\subsection{Methodological Dimension}

In this dimension the methodological approaches are integrated into MINERVA. For the definition of the methodology for the continuous business process improvement we are currently evaluating the continuous improvement process PMCompetisoft integrated into COMPETISOFT [29], to adapt it. For the Service Oriented development a previous defined methodology is integrated which defined a core set of disciplines, activities, deliverables and roles to be added to the development process used in the organization, which we briefly present in the following but can be seen in detail in [14]. In Fig. 3 the Business Modeling, Design and Implementation Disciplines, its activities and execution flow are shown as a BPMN process model. The methodology defines several related activities to develop service oriented systems from business processes, starting with business process modeling where the use of process patterns [30] is recommended. Conceptually the methodology can be added as a plug-in to the development software process used in the organization, adding the new elements to guide the service oriented development from business processes. To make this integration effective, we are working on its implementation with the Software Process Engineering Metamodel (SPEM) [31] using the Eclipse Process Framework Composer (EPF Composer) [32]. It also defines input and output deliverables (i.e. Services document) and responsible and participant roles for the defined activities, as well as a detailed description of objectives and tasks to be carried out when performing the activity, which are summarized in table 1 . 


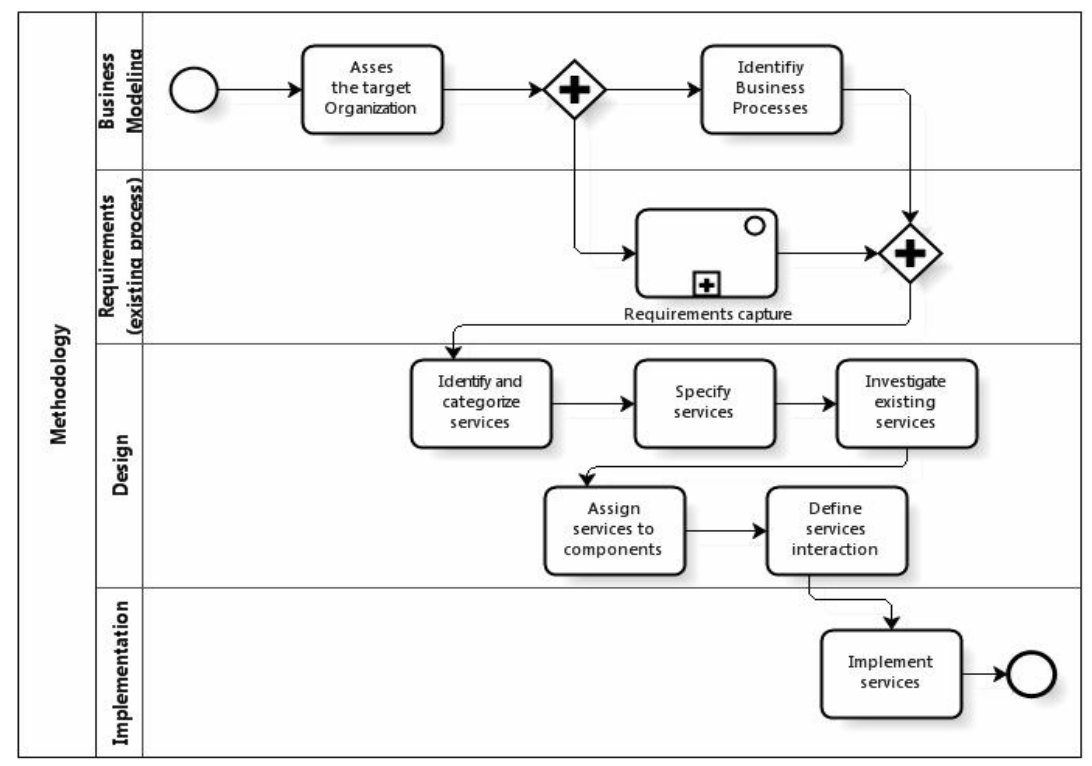

Fig. 3. Service Oriented development Methodology as BPMN process

Table 1. Elements defined in the methodology related to the presented activities

\begin{tabular}{|c|c|c|c|}
\hline Activity & Objective & Inputs/Outputs & Roles \\
\hline $\begin{array}{c}\text { Assess the target } \\
\text { Organization (MN1) }\end{array}$ & $\begin{array}{l}\text { Obtain the organization map, } \\
\text { its processes and technologies }\end{array}$ & $\begin{array}{l}\text { I:Meetings with clients/ } \\
\text { O:Evaluation of the Target } \\
\text { Organization Document }\end{array}$ & $\begin{array}{l}\text { Analyst, } \\
\text { Architect }\end{array}$ \\
\hline $\begin{array}{l}\text { Identify Business } \\
\text { Processes (MN2) }\end{array}$ & $\begin{array}{l}\text { Model business processes, } \\
\text { flow, involved roles, associated } \\
\text { functionalities }\end{array}$ & $\begin{array}{l}\text { I: Evaluation of the Target } \\
\text { Organization Document, } \\
\text { minutes of meetings with } \\
\text { clients, O:BP Document }\end{array}$ & $\begin{array}{l}\text { Architect, } \\
\text { Analyst }\end{array}$ \\
\hline $\begin{array}{l}\text { Identify and categorize } \\
\text { services (D1) }\end{array}$ & $\begin{array}{l}\text { Define and classify the services } \\
\text { to carry out the business } \\
\text { processes and functionalities }\end{array}$ & $\begin{array}{l}\text { I: SW Architecture, BP, } \\
\text { Requirements and Services } \\
\text { Documents, O: Services } \\
\text { Document,SWArchitecture }\end{array}$ & $\begin{array}{l}\text { Architect, } \\
\text { Analyst, } \\
\text { Developer }\end{array}$ \\
\hline Specify services (D2) & $\begin{array}{l}\text { Define contract of services, } \\
\text { operations, parameters, etc. }\end{array}$ & I/O:Services Document & $\begin{array}{l}\text { Architect, } \\
\text { Analyst }\end{array}$ \\
\hline $\begin{array}{l}\text { Investigate existing } \\
\text { services (D3) }\end{array}$ & $\begin{array}{l}\text { Reuse services, components, } \\
\text { implemented functionalities }\end{array}$ & $\begin{array}{l}\text { I/O: Services Document and } \\
\text { Catalogue }\end{array}$ & $\begin{array}{l}\text { Architect, } \\
\text { Analyst }\end{array}$ \\
\hline $\begin{array}{l}\text { Assign services to } \\
\text { components (D4) }\end{array}$ & Define service implementation & $\begin{array}{l}\text { I: Services and Design } \\
\text { Documents, O: Services and } \\
\text { Implementation Docs. }\end{array}$ & $\begin{array}{l}\text { Architect, } \\
\text { Developer }\end{array}$ \\
\hline $\begin{array}{l}\text { Define services } \\
\text { interaction (D5) }\end{array}$ & $\begin{array}{l}\text { Define sequences of invocation } \\
\text { of services to carry out the } \\
\text { business processes }\end{array}$ & $\begin{array}{l}\text { I: BP, Services and } \\
\text { Requirements Documents, } \\
\text { O:Services and } \\
\text { Implementation Docs. }\end{array}$ & $\begin{array}{l}\text { Architect, } \\
\text { Analyst, } \\
\text { Developer }\end{array}$ \\
\hline $\begin{array}{l}\text { Implement } \\
\text { services (I1) }\end{array}$ & $\begin{array}{l}\text { Build the services as they were } \\
\text { designed }\end{array}$ & $\begin{array}{l}\text { I: Services, Design and } \\
\text { Implementation Docs., } \\
\text { O: Implemented service }\end{array}$ & Developer \\
\hline
\end{tabular}




\subsection{Tool Dimension}

The tool dimension gives support to the defined methodologies and automation of transformations between the different models used in MINERVA. The integrated environment, which is currently under definition, proposes the use of different tools for each phase of the business process lifecycle to support the defined concepts in all framework dimensions. For the business process modeling we are currently evaluating Bizagi [33] and Visual Paradigm [34] tools, among others, which provide BPMN. One of the main outputs of this phase is the business process model in a suitable format as XMI [35], so it could be later imported by other tools, like tools for simulation and validation of models or software development. For the software development support for business processes in the Configuration phase, the use of IDE Eclipse [36] is proposed, with a plug-in to load the business process model made, i.e. the Visual Paradigm plug-in [34] or the SOA Tools Platform Project (STP) [37].

To transform the business process models into service oriented UML artifacts, applying model driven development principles, these have to be marked with some information, i.e. the type of activity like "service task" with input and output specified messages. So, to obtain, for example, a service class model from a business process model, QVT transformations are defined from BPMN to the SoaML using the Eclipse plug-in MediniQVT [38], supported by the defined ontologies. After applying the QVT transformations, a PIM will be obtained in the SoaML profile, from which to generate the PSM to the desired technology platform. At the moment of generating the specification of the business processes in BPEL/XPDL, some marks have to be used too, to allow the generated components to be invocated from the process execution flow. Then, from the execution of the process, log files will be obtained containing the defined information to collect, to be analyzed in the Evaluation phase using the ProM [39] tool by means of the different plug-ings it provides.

\section{Related Work}

Some of the most relevant works in the area comprising the integration of MDD and SOC paradigms to business processes are: In [40] models, metamodels and transformations between them are defined to obtain a service composition model which expresses the interaction of services to perform business processes. In [41] they integrate a business value model from which to derive software artifacts. [42] proposes a business rules driven approach for the development of adaptive collaborative service oriented business processes, defining three dimensional views: collaboration aspects, business and technical requirements. In [43] a service oriented design approach is proposed, to relate services modeled in different levels of abstraction: business and application, with techniques based on ISDL: profiles to relate models and model conformance. In [44] models and metamodels for services are defined to relate them to business processes and the underlying architecture, focusing the derivation of services on three architectures: brokerless, centralized and decentralized broker. [45] defines patterns to guide the definition, transformation and implementation of technical processes using software services from business processes. [46] proposes a model driven approach to relate business process with software services in a target (distribute) three layered architecture. The business 
process are modeled in UML deriving an analysis model which is mapped to the design model defined in the existing target architecture, and then to the implementation model. [47] also proposes a model driven approach for collaborative service oriented architecture, to transform BPMN into UML and BPEL models. It defines a collaborative SOA metamodel composed of three views: service, information and process; the business process model is transformed to each one.

Other proposals that integrates only one of the MDD or SOC paradigms to business processes are: [48] defines a set of transformation patterns to transform a business process into a technical process based on existing services provided by internal systems, defining levels for the quality of the transformation. Also in [49] a pattern based technique is used in a layered architecture defined in a framework for EI architectures, for service identification and transformation from business models to service architecture, organizing patterns (process, domain, SOA) in catalogues. In [50] a four level architecture and a design process to develop B2B applications are defined, selecting the services to realize business process from an existing repository or catalog. In [51] a three level conceptual framework is defined to relate business process with implemented services, with five layers including a service mediating one where a Service Invocation Coordinator (SIC) implements service invocation. In [52] UML artifacts like use cases, activity and collaboration diagrams are automatically obtained from BPMN business processes. [53] defines phases, activities and artifacts for services development from business processes, and implementation as WS. [54] proposes modeling of business process realization by services diagrams, integrating a Business Services Model (BSM) mediator between requirements and implementation.

\section{Conclusions and Future Work}

We have presented the ideas and work behind the definition of the MINERVA framework for the continuous business processes improvement, based on the application of the SOC and the MDD paradigms to business processes. The implementation of business processes by software services helps in closing the gap between business and IT areas. Our proposal includes the integration of business people into the business process modeling stage in the development process. A service oriented methodology based on business processes is integrated, and all the stages are supported by a variety of tools. An ontology is being constructed that allows defining and relating concepts from business processes to service orientation. The metamodels from which we are defining the QVT transformations, use those concepts allowing us to understand the elements we want to obtain for services models from business process models. The automatic generation of services from business processes will serve as a basis for the improvement of the implementation and execution of service based business processes. We are also working in the definition of the continuous improvement process based on business process lifecycle, which will guide the activities to perform for assessing the modeling and execution of business process to find improvement opportunities. For helping in doing the assessment, modeling and execution measures will also be integrated, basing its elements, relations and use in the defined ontology. 
Acknowledgments. This work has been partially funded by the Agencia Nacional de Investigación e Innovación (ANII) from Uruguay, ALTAMIRA project (Junta de Comunidades de Castilla-La Mancha, Fondo Social Europeo, PII2I09-0106-2463) and INGENIO project (Junta de Comunidades de Castilla-La Mancha, Consejería de Educación y Ciencia, PAC08-0154-9262).

\section{References}

1. Business Process Management Initiative, http: / /www . bpmi . org/

2. Smith, H., Fingar, P.: Business Process Management: The third wave. Meghan-Kieffer (2003) 978-0929652337

3. Weske, M.: BPM Concepts, Languages, Architectures. Springer, Heidelberg (2007) 978-3540-73521-2

4. Mendling, J.: Metrics for process models. Springer, Heidelberg (2008) 978-3-540-89223-6

5. van der Aalst, W.M.P., ter Hofstede, A., Weske, M.: Business Process Management: A Survey. In: van der Aalst, W.M.P., ter Hofstede, A.H.M., Weske, M. (eds.) BPM 2003. LNCS, vol. 2678, pp. 1-12. Springer, Heidelberg (2003)

6. Papazoglou, M., Traverso, P., Dustdar, S., Leymann, F.: Service-Oriented Computing: State of the Art and Research Challenge. IEEE Computer Society, Los Alamitos (2007)

7. Krafzig, D., Banke, K., Slama, D.: Enterprise SOA, Service Oriented Architecture: Best Practices, 1st edn. Prentice Hall, Englewood Cliffs (2005) 978-0131465756

8. Erl, T.: SOA: Concepts, Technology, and Design. Prentice-Hall, Englewood Cliffs (2005) 978-0131858589

9. Web Services Architecture (WSA), W3C, http: / /www.w3 . org/TR/ws-arch/

10. Mellor, S., Clark, A., Futagami, T.: Model Driven Development - Guest editors introduction. IEEE Computer Society, Los Alamitos (September/October 2003)

11. Stahl, T., Volter, M., et al.: Model-Driven Software Development, Technology, Engineering, Management. John Wiley \& Sons, Ltd., Chichester (2006) 978-0470025703

12. Model Driven Architecture (MDA) v. 1.0.1, OMG (2003), http : / / www . omg . org/maa

13. Object Management Group (OGM), http : / / www . omg . org

14. Delgado, A., Ruiz, F.: Towards a Service-Oriented and Model-Driven framework with business processes as first-class citizens. In: 2nd Int. Conf. on Business Process and Services Computing (BPSC 2009), Leipzig (2009)

15. Business Process Maturity Model (BPMM), OMG, http: / / www . omg . org/spec/BPMM

16. Sánchez, L., Delgado, A., Ruiz, F., García, F., Piattini, M.: Measurement and Maturity of Business Processes. In: Cardoso, J., van der Aalst, W. (eds.) Handbook of Research on Business Process Modeling, pp. 532-556. Information Science Ref., IGI Global (2009)

17. Business Process Modeling Notation (BPMN), OMG, http : / /www . omg . org / spec / BPMN/

18. Soa Modeling Language (SoaML), OMG, http: / /www . omg . org/spec/SoaML/

19. Query/Views/Transformations(QVT)v.1.0,OMG (2008), http : / / www . omg . org/spec / QVT/1.0

20. Web Services Business Process Execution Language (WS-BPEL), OASIS, http: / / docs.oasis-open.org/wsbpel/2.0/

21. XML Process Definition Language (XPDL), v. 2.1, WfMC, http://www.wfmc.org/xpdl.html 
22. van der Aalst, W.M.P., Reijers, H.A., Medeiros, A.: Business Process Mining: an Industrial Application. Information Systems 32(5), 713-732 (2007)

23. Gruber, T.R.: A translation approach to portable ontology specifications. Knowledge Acquisition 5(2) (1993)

24. Business Process Definition Metamodel (BPDM), OMG, http: / / www . omg.org/spec/BPDM

25. García, F., et al.: Towards a Consistent Terminology for Software Measurement. Information and Software Technology 48, 631-644 (2005)

26. Delgado, A., Ruiz, F., García - Rodríguez de Guzmán, I., Piattini, M.: Towards an ontology for service oriented modeling supporting business processes. In: 4th International Conference on Research Challenges in Information Science (RCIS 2010) (2010)

27. Soa Reference Model, Oasis, http: / / www . oasis-open.org/committees/soa-rm/

28. Soa Ontology, Open Group, http://www.opengroup.org/projects/soaontology/

29. COMPETISOFT - Process Improvement for Iberoamerican SME, CYTED, http: / /alarcos.infcr.uclm.es/Competisoft

30. van der Aalst, W.M.P., ter Hofstede, A.H.M., Kiepuszewski, B., Barros, A.P.: Workflow Patterns. Distributed and Parallel Databases 14, 5-51 (2003)

31. Software Process Engineering Metamodel (SPEM), OMG, http: / / www . omg . org/spec/SPEM/

32. Eclipse Process Framework Composer (EPF Composer), http: / / www.eclipse.org/epf/

33. BizAgi Process Modeler, http://www.bizagi.com/

34. Visual Paradigm, http://www.visual-paradigm.com/

35. XML Metadata Interchange (XMI), OMG, http: / /www . omg . org/spec/XMI /

36. Eclipse, The Eclipse Foundation, http: / /www. eclipse.org/

37. Eclipse SOA Tools Platform Project (STP), http: / /www. eclipse.org/stp/

38. Medini QVT, ikv++ technlogies ag, http://projects.ikv.de/qvt

39. ProM, Process Mining Group, Eindhoven University of Technology, Eindhoven, The Netherlands, http://prom.win.tue.nl/research/wiki

40. de Castro, V., Marcos, E., López Sanz, M.: A model driven method for service composition modelling: a case study. Int. J. Web Engineering and Technology 2(4) (2006)

41. de Castro, V., Vara Mesa, J.M., Herrmann, E., Marcos, E.: A Model Driven Approach for the Alignment of Business and Information Systems Models. In: 9th Mexican International Conference on Computer Science (ENC 2008) (2008)

42. Orriens, B., Yang, J., Papazoglou, M.: A Rule Driven Approach for Developing Adaptive Service Oriented Business Collaboration. In: Int. Conf. on Services Computing (SCC 2006) (2006)

43. Quartel, D., Dijkman, R., van Sinderen, M.: An approach to relate business and application services using ISDL. In: 9th Int. Enterprise Computing Conference, EDOC 2005 (2005)

44. Roser, S., Bauer, B., Muller, J.: Model- and Architecture-Driven Development in the Context of Cross-Enterprise Business Process Engineering. In: Int. Conference on Services Computing (SCC 2006) (2006)

45. Zdun, U., Hentrich, C., Dustdar, S.: Modeling Process-Driven and Service-Oriented Architectures Using Patterns and Pattern Primitives. ACM Transactions on the Web 1(3), Article 14 (2007) 
46. Herold, S., Rausch, A., Bosl, A., Ebell, J., Linsmeier, C., Peters, D.: A Seamless Modeling Approach for Service-Oriented Information Systems. In: 5th International Conference on Information Technology: New Generations (ITNG 2008) (2008)

47. Touzi, J., Benaben, F., Pingaud, H., Lorré, J.P.: model-driven approach for collaborative service-oriented architecture design. Int. Journal of Prod. Economics 121(1) (2009)

48. Henkel, M., Zdravkovic, J.: Supporting Development and Evolution of Service-based Processes. In: International Conference on e-Business Engineering, ICEBE 2005 (2005)

49. Gacitua-Decar, V., Pahl, C.: Pattern-based business-driven analysis and design of service architectures. In: 3rd Int. Conf. on Software and Data Technologies, ICSOFT 2008 (2008)

50. Baghdadi, Y.: ABBA: an architecture for deploying business-to-business electronic commerce applications. Electronic Commerce Research and Applications 3(2) (2004)

51. Hu, J., Grefen, P.: Conceptual framework and architecture for service mediating workflow management. Information and Software Technology 45(13) (2003)

52. Liew, P., Kontogiannis, K., Tong, T.: A Framework for Business Model Driven Development. In: 12th Int. Workshop on SW Tech. and Engineering Practice, STEP 2004 (2004)

53. Papazoglou, M., van den Heuvel, W.: Service-oriented design and development methodology. Int. J. Web Engineering and Technology 2(4), 412-462 (2006)

54. Rychly, M., Weiss, P.: Modeling of Service Oriented Architecture: from business process to service realization. In: 3rd Int. Conf. on Evaluation of Novel Approaches to Software Engineering, ENASE 2008 (2008) 